\title{
Recursos na internet e dobraduras para poliedros estrelados: uma proposta para 0 trabalho no ensino médio
}

\author{
Internet resources and origami for stellar polyhedra: \\ a proposal for teaching in high school
}

Wellington Gonçalves Lemos

Marcelo Almeida Bairral

\begin{abstract}
Resumo
Dos conteúdos trabalhados na Matemática escolar atual os Poliedros Estrelados são inexistentes nas propostas oficiais nacionais. Pela sua beleza visual e magnitude conceitual os Poliedros Estrelados despertam interesse nos professores para a sua inserção em sala de aula. Com a proposição deste artigo apresentaremos recursos que podem ser utilizados pelo docente para o trabalho com Poliedros Estrelados no Ensino Médio, mostraremos sítios da Internet que abordam o assunto, exemplificaremos animações em 3D e ilustraremos módulos de dobraduras que estamos desenvolvendo. Além de possibilidades de inovações curriculares, proporemos uma arquitetura (cognitiva, comunicativa e representacional) paras as aulas de Matemática. Essa arquitetura desafia os educadores a pensar em diferentes possibilidades para análise do processo ensino-aprendizagem.
\end{abstract}

Palavras-chave: geometria; poliedros regulares; ensino médio; informática; origami.

\footnotetext{
Abstract

Among the content of current school mathematics in Brazil, stellar polyhedra does not exist in official national curriculum proposals. The visual beauty and conceptual magnitude of these kinds of polyhedra awaken interest among teachers to include them in their classroom curriculum. In this article, we present resources that high school teachers can use to work with stellar polyhedra. We show Internet sites that explore this topic, exemplify 3-D animations, and illustrate Origami modules that we are constructing. Besides possibilities of curricular innovations, we propose an architecture (cognitive, communicative and representative) for mathematics classrooms. This architecture challenges educators
} 
to think in different ways to analyze the teaching-learning process.

Keywords: geometry; stellar polyhedra; High School; informatics; origami.

\section{Introdução}

O Trabalho com geometria possibilita o desenvolvimento de habilidades como as de experimentar, representar e argumentar, além de instigar a imaginação e a criatividade. Essas habilidades, dentre outras, permitirão o entendimento das estruturas e representações geométricas que estão presentes na natureza, nas artes e nas edificações.

Diretrizes curriculares (nacionais e internacionais) têm enfatizado que a Matemática escolar deve permitir que os alunos adquiram uma compreensão relacional e conceitual do conteúdo matemático e desenvolvam a habilidade própria para o pensamento matemático. Desta forma, a instrução Matemática deve fornecer experiências que encorajem e permitam que os alunos se tornem solucionadores de problemas matemáticos, se comuniquem e raciocinem Matemática e diferentemente.

Um trabalho com geometria que rompa com a perspectiva axiomática e com a decoreba de fórmulas está distante da maioria das escolas brasileiras. Um caso particular de inexistência na prática docente atual são os Poliedros Estrelados. Além de inexistentes nas salas de aula e livros didáticos, estes não constam de propostas oficiais nacionais, por exemplo, nos Parâmetros Curriculares Nacionais. Pela sua beleza estética e magnitude conceitual referidos poliedros despertam interesse nos professores para o seu trabalho em sala de aula.

Admitimos que na educação científica o professor necessita de diferentes materiais para ajudá-lo na criação de situações pedagógicas desafiadoras e também para auxiliá-lo no equacionamento de situações previstas em seu planejamento, mas imprevistas na prática devido aos questionamentos dos alunos durante as aulas. Com essa perspectiva, após tecermos comentários sobre algumas considerações curriculares que fundamentam o estudo, nesse artigo (i) apresentaremos recursos que podem ser utilizados pelo docente para o trabalho com Poliedros Estrelados no Ensino Médio, (ii) mostraremos sítios da Internet que abordam o assunto e (iii) exemplificaremos possibilidades de atividades. Além de possibilidades de inovações curriculares, proporemos uma arquitetura (cognitiva, comunicativa e representacional) paras as aulas de Matemática (LEMOS e BAIRRAL, 2007). Essa arquitetura, hipertextual, considera a motivação que o estudante tem para o uso da informática e desafia os educadores a pensar em diferentes possibilidades para análise do seu aprendizado. 


\section{Perspectivas curriculares da geometria}

Pensar a educação geométrica no currículo atual implica repensar a matemática, o seu currículo e suas finalidades. Conforme sublinhou Abrantes (1999), ao despertar para a intuição e para visualização e recorrer, com naturalidade, à manipulação de materiais, a geometria propicia um ensino fortemente baseado na realização de descobertas e na resolução de problemas.

O ensino de Matemática deve ser primordial, pois essa ciência faz parte de um patrimônio cultural importante na organização da nossa sociedade. Como tal, a geometria que se deve ensinar deve ser principalmente, e ao longo de toda a escolaridade, a geometria que nos permite interpretar e intervir no espaço em que vivemos. Esta inclui a visualização de objetos, a sua representação, a manipulação dessas representações e a criação de novos objetos. Inclui, também, a resolução de problemas de aplicação da geometria a situações da vida real, a sua ligação à arte e outras coisas em comum (BASTOS, 1999).

De acordo com Lorenzato (2006) os materiais didáticos utilizados pelo professor podem desempenhar várias funções, conforme o objetivo a que se presta e, por isso, o professor deve se perguntar para que ele deseja utilizar os materiais didáticos. Por exemplo: apresentar um assunto, motivar os alunos, auxiliar a memorização dos resultados ou facilitar a redescoberta pelos alunos? São as respostas a essas perguntas que indicaram a escolha dos materiais didáticos mais convenientes a determinada aula.

No entanto, conforme sublinhou Veloso (1998), a realização de atividades manipulativas ou visuais não garante a aprendizagem. Para que esta efetivamente aconteça faz-se necessária uma atividade mental por parte do aluno. Dessa forma, os materiais didáticos podem ser excelentes catalisadores para o aluno construir seu saber matemático. Para o estudante, mais importante do que conhecer as verdades matemáticas é obter a alegria da descoberta, a percepção de sua capacidade, a certeza de que vale a pena procurar soluções e fazer constatações, a satisfação do sucesso e compreender que a matemática não é um "monstro de sete cabeças", mas um campo onde ele pode navegar, interagir, reconstruir e aprender.

Ao repensar a prática pedagógica em geometria, o origami, arte oriental milenar de dobradura de papel, surgiu como um instrumento instigante para a revitalização dessa prática. 0 Origami é uma forma de representação visual/escultural, definida principalmente pela dobradura do meio (usualmente papel). A Matemática é essencialmente bonita, e o origami nos mostra algo dessa beleza, numa maravilhosa relação entre ciência e arte. De uma ou mais folhas simples de papel, emerge um universo de formas. Em uma determinada época acreditava-se que o origami era uma simples arte de imitação, mas o tempo mostrou que não é bem assim, porque não é possível captar a essência de um objeto se antes não conhecermos o objeto a ser reproduzido com a dobradura. 
Uma potencialidade dos materiais didáticos é revelada no momento de sua construção pelos próprios alunos, pois é durante esta que surgem imprevistos e desafios, os quais levam os alunos a fazer conjecturas e a descobrir caminhos e soluções. Segundo Kaleff (2004), o processo de confecções dos poliedros é bastante simples e as vantagens do material são muitas: baixo custo, facilidade de uso, rapidez no processo, etc.

Alsina (apud SARAIVA, COELHO e NETO, 2002) afirma que no ensino da matemática a geometria deve ser útil para todos: o conhecimento matemático do espaço. Uma geometria baseada na intuição e na experimentação aconselhada pelo sentido comum; rica em temas de representações e interpretações; capaz de ordenar, classificar e mover figuras planas e espaciais; audaz na combinação de linguagens diversas (gráficas, analíticas e simbólicas); apoiada no rigor das definições sobre fatos relevantes; com técnicas diversas para medir, construir e transformar, induzindo à compreensão do diálogo plano-espaço; aberta à interdisciplinaridade com as ciências e com as artes; paradigma da modernização matemática. Esta é a geometria com a qual gostaríamos de educar a todos.

Assumimos que não é apenas a inserção de computadores nos processos de ensino que garantem melhorias no aprendizado. Torna-se necessário redimensionar a prática docente e a função do professor. As abordagens de um ensino mais dinâmico e inovador, onde os conteúdos matemáticos passam a estar articulados com diferentes processos e artefatos, estão sendo consideradas na seguinte arquitetura e dinâmica da aula de Matemática como mostra a Figura 1.

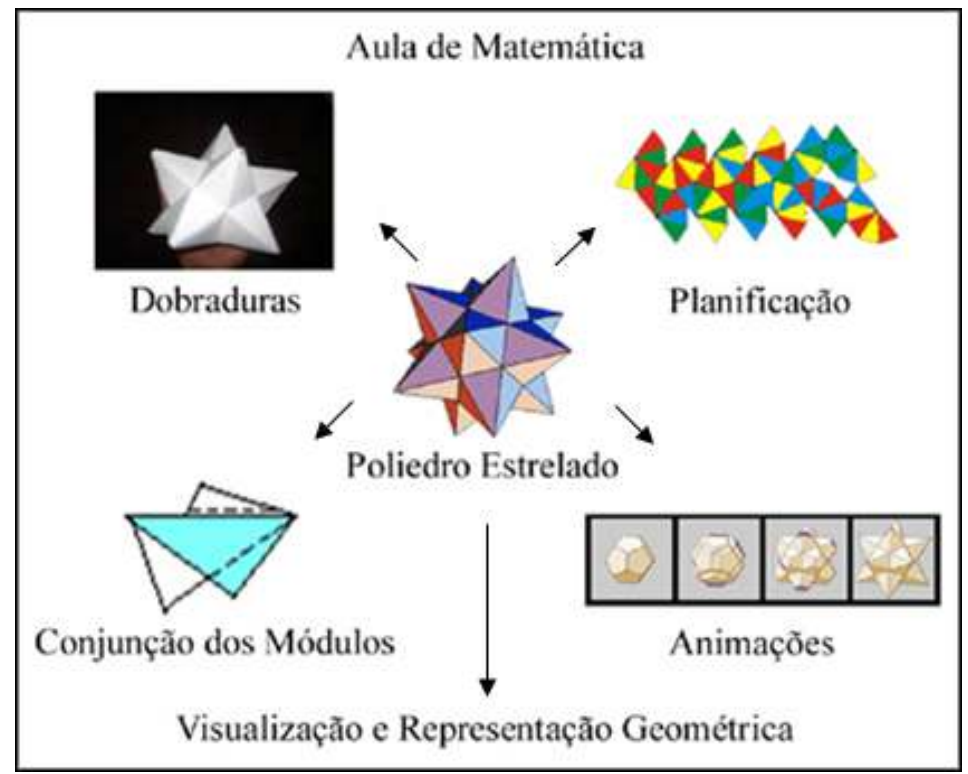

Figura 1: Proposta de uma arquitetura para as aulas de matemática

Nossa arquitetura, não linear e não hierárquica, preconiza uma educação geométrica onde as atividades desenvolvem diferentes processos: visualização, conceituação, representação, 
comunicação, construção, manipulação, argumentação e justificativas. Vejamos como estamos estruturando o trabalho com Poliedros Estrelados nessa arquitetura.

\section{Estudo teórico sobre os poliedros regulares}

Além dos aspectos teóricos elucidados anteriormente, estamos tratando de um grupo específico de Poliedros: os Poliedros Estrelados Regulares ou Sólidos de Kepler-Poinsot. Este componente conceitual irá articular os aspectos curriculares com os cognitivos, elementos que serão considerados na elaboração de atividades práticas e na análise.

Os Poliedros Regulares são também conhecidos como Platônicos. São assim chamados por terem sido estudados e divulgados por Platão. São conhecidos como Regulares, pois todas as faces, ângulos e ângulos entre as faces são sempre os mesmos. Todo ângulo sólido tem que ter um mínimo de três faces. Analisando os Polígonos Regulares vemos que os possíveis geradores de ângulos sólidos são os de ângulo interno menor que $120^{\circ}$, pois a soma dos ângulos internos das faces deve ser menor que $360^{\circ}$. Portanto, os Polígonos Regulares que formam os cinco Poliedros Regulares são: o Triângulo $\left(3 \times 60^{\circ}=180^{\circ}\right)$, o Quadrado $\left(3 \times 90^{\circ}=270^{\circ}\right)$ e o Pentágono $\left(3 \times 108^{\circ}=324^{\circ}\right)$.

Existem 5 Poliedros Regulares conforme mostra a Tabela 1.

Tabela 1:- Poliedros platônicos.

\begin{tabular}{lllll}
$\begin{array}{l}\text { Tetraedro } \\
\mathbf{3} \text { faces por }\end{array}$ & $\begin{array}{l}\text { Hexaedro } \\
\mathbf{3} \text { faces por } \\
\text { vértice }\end{array}$ & $\begin{array}{l}\text { Octaedro } \\
\mathbf{4} \text { faces por } \\
\text { vértice }\end{array}$ & $\begin{array}{l}\text { Dodecaedro } \\
\text { vértice }\end{array}$ & $\begin{array}{l}\text { Icosaedro } \\
\mathbf{3} \text { faces por } \\
\text { vértice }\end{array}$ \\
\hline
\end{tabular}

Um Poliedro Convexo é Regular quando as suas faces são Polígonos Regulares iguais entre si e em cada vértice se encontram (concorrem) o mesmo número de faces. Num poliedro deste tipo as faces não se distinguem entre si, o mesmo sucedendo às arestas (e aos vértices). Portanto, os cinco Poliedros da Tabela 1 são exemplos de Poliedros Convexos Regulares.

Será que todos os Poliedros Regulares são Convexos? Johannes Kepler, em 1619, descobriu dois Poliedros que são simultaneamente Regulares e não Convexos - o Pequeno Dodecaedro Estrelado e o Grande Dodecaedro Estrelado. Dois séculos mais tarde provar-se-ia que 
existem apenas nove Poliedros nestas circunstâncias: os cinco Sólidos Platônicos e quatro Poliedros Regulares não Convexos - os Poliedros de Kepler-Poinsot.

\section{Processo de estrelação}

Para compreender como se obtêm os Poliedros Estrelados é importante entender o que são Polígonos Estrelados. O processo de prolongar os lados de um polígono é chamado de estrelação. Se o processo de estrelação gerar um novo polígono e, se o polígono gerado não for dado pela sobreposição de polígonos diremos que o polígono é estrelado. Por exemplo, a Figura 2 mostra que a estrelação do pentágono gera um polígono estrelado chamado pentagrama e na Figura 3 podemos verificar que a estrelação do hexágono gera um polígono não estrelado, pois esse polígono é a sobreposição de dois triângulos.

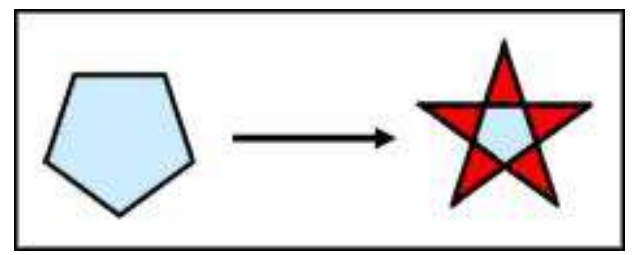

Figura 2 : Processo de estrelação no pentágono regular

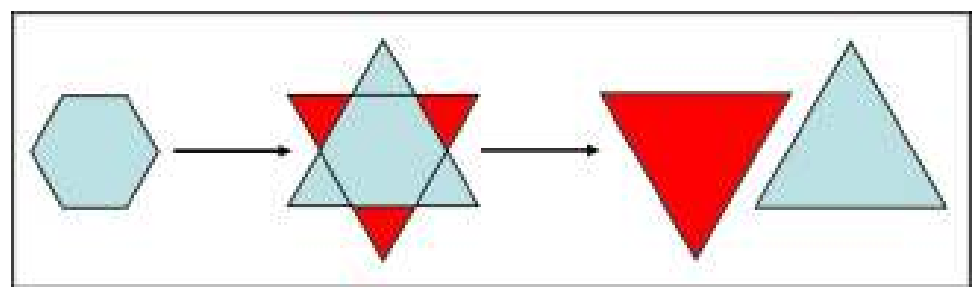

Figura 3 : Processo de estrelação no hexágono regular

Alguns polígonos podem admitir mais do que uma estrelação, por exemplo, o heptágono. Veja a Figura 4.

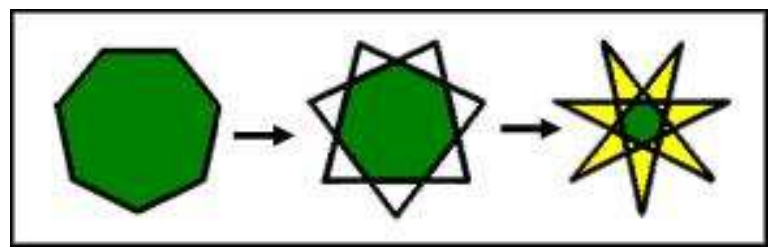

Figura 4: Processo de estrelação no heptágono regular

Outra forma de verificar se o polígono é estrelado ou não seria ir "caminhando" por todos os seus lados sem passar duas vezes por um mesmo lugar, isto é, saindo de uma das "pontas" do polígono e "caminhando" até a próxima e assim sucessivamente até terminar. Se o polígono for 
estrelado, será possível "caminhar" por todos os lados sem repeti-los. Caso contrário, o polígono não é estrelado.

\section{Sólidos ou poliedros estrelados}

O processo de obter Sólidos Estrelados é semelhante ao dos Polígonos, ou seja, prolongam-se as faces de Sólidos e, caso elas se encontrem, obtemos os Poliedros Estrelados. Assim como acontece nos Polígonos, os Poliedros podem admitir mais de uma estrelação. Por exemplo, o Dodecaedro possui 3 estrelações. Veja a Figura 5.

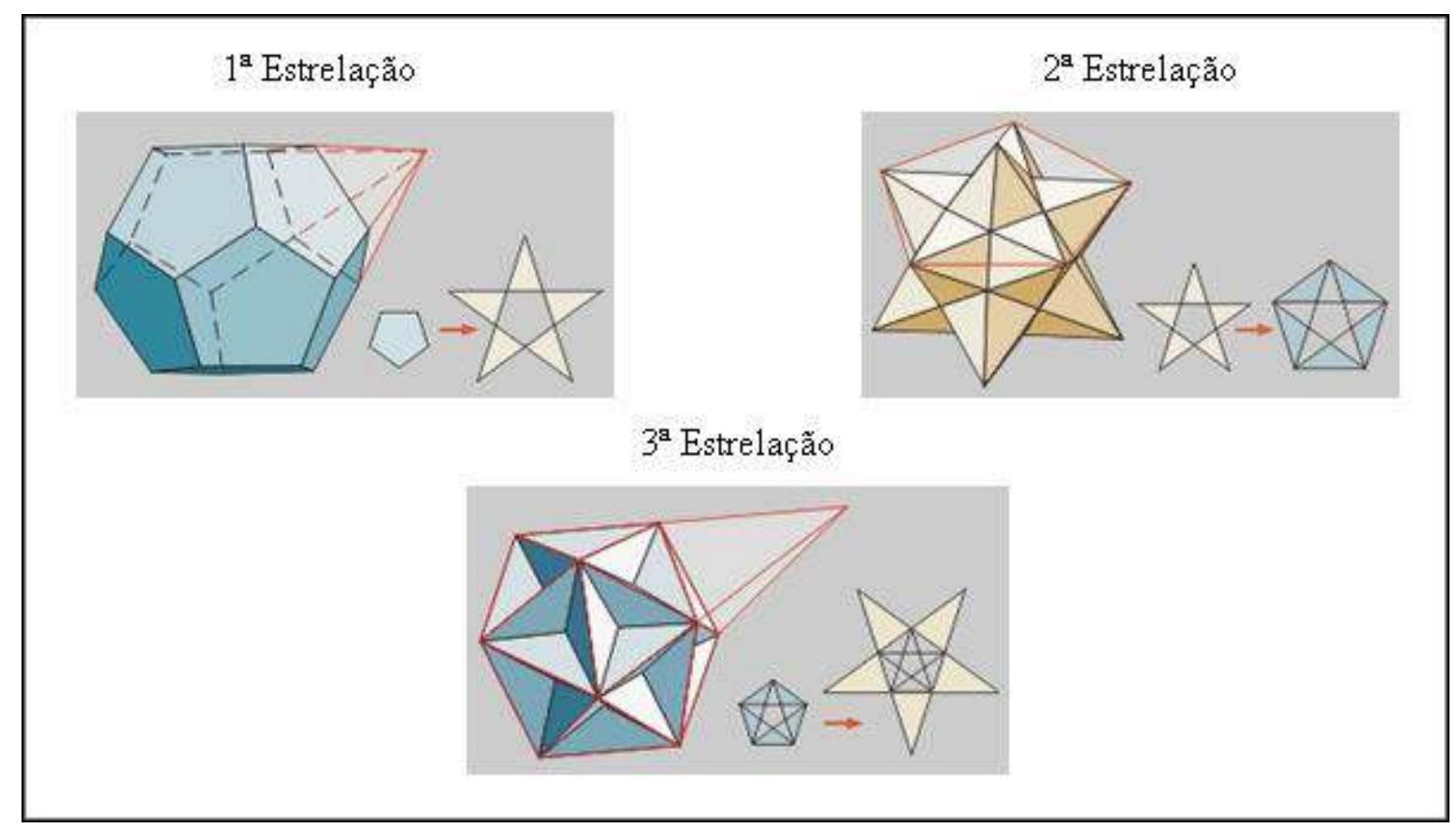

Figura 5 : As três estrelações do dodecaedro

Fonte: http://www.edu.xunta.es/contidos/premios/p2004/b/

poliedros/estrelas/estrelas.htm

Prolongando as faces de um tetraedro, de um cubo ou de um octaedro, não é possível obter novos Poliedros. Pelo contrário, partindo do dodecaedro é possível obter o poliedro da Figura 6. 


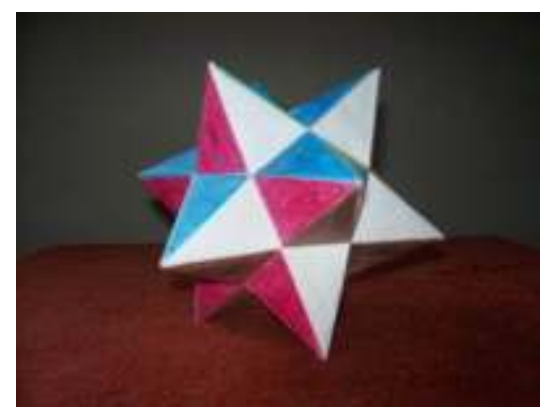

Figura 6: Pequeno dodecaedro estrelado

O Pequeno Dodecaedro Estrelado possui 12 faces em forma de Pentagrama, 12 vértices e 30 arestas. Prolongando suas faces é possível obter o poliedro da Figura 7.

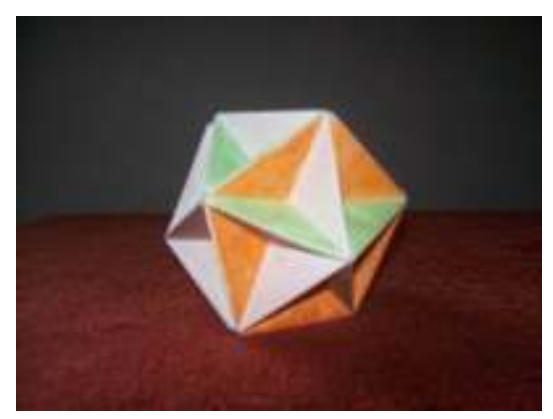

Figura 7 : Grande dodecaedro

O Grande Dodecaedro possui 12 faces em forma de Pentágonos, 12 vértices e 30 arestas. Prolongando suas faces é possível obter o poliedro da Figura 8.

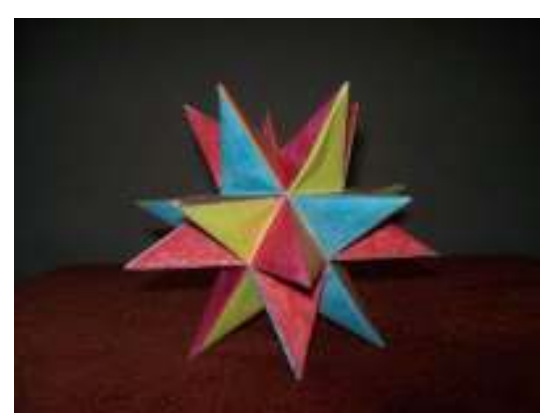

Figura 8: Grande dodecaedro estrelado

O Grande Dodecaedro Estrelado possui 12 faces em forma de Pentagrama, 20 vértices e 30 arestas.

O Pequeno Dodecaedro Estrelado (Figura 6) e o Grande Dodecaedro Estrelado (Figura 8) podem, à primeira vista, parecer respectivamente um dodecaedro e um icosaedro, sobre cujas 
faces foram construídas Pirâmides Regulares todas iguais entre si; a altura destas Pirâmides é a altura "certa" para que os sessenta Triângulos que representam as faces laterais, tomados cinco a cinco, estejam sobre um mesmo plano e rodeiem um Pentágono com o qual formam um Pentagrama (as cores das figuras evidenciam esses planos).

Os dois Poliedros podem, portanto, ser obtidos unindo nos seus vértices (cinco a cinco, ou três a três) doze Pentágonos Regulares Estrelados todos iguais, de modo que as "faces" sejam unidas uma à outra ao longo dos seus lados, como nos Poliedros usuais, mas por forma que se intersectem escondendo os Pentágonos centrais de cada Pentagrama. Do ponto de vista matemático os referidos Poliedros foram estudados pela primeira vez por volta do ano 1600 pelo cientista alemão Kepler (1571-1630), mas já eram conhecidos há muito tempo. O pequeno dodecaedro estrelado, por exemplo, encontra-se representado no pavimento da basílica de São Marcos, em Veneza, num embutido em mármore de 1420, atribuído a Paolo Uccello.

Outro poliedro que dá origem a muitas estrelações é o Icosaedro. Neste século, Coxeter provou a existência de 59 estrelações do Icosaedro. Do ponto de vista histórico, interessa-nos particularmente a 16a estrelação, o chamado de Grande Icosaedro onde suas faces são Triângulos Eqüiláteros em número de 20 , os vértices em número de 12 e as arestas em 30 como mostra a Figura 9.

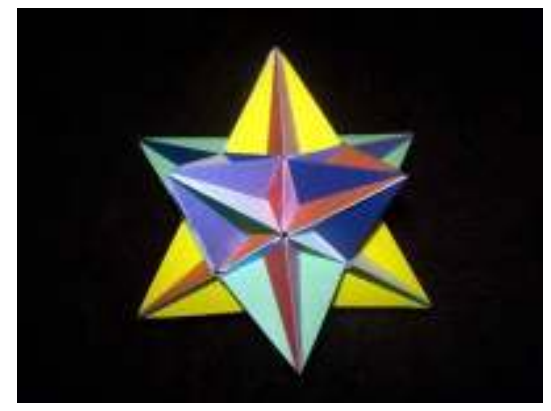

Figura 9: Grande icosaedro

Em todos os Poliedros Estrelados, deve-se notar que para visualizar as faces e distingui-las se utilizam várias tonalidades de cor onde cada face tem um tom diferente. Deve-se notar também que as faces se intersectam, como já foi observado. Para interpretar esses Sólidos como verdadeiros Poliedros é essencial compreender quais são as faces, as arestas e os vértices. 


\section{Conjunção dos módulos e montagem através de dobraduras}

A conjunção dos módulos é simples, porém existe um grau de complexidade no momento da construção das peças. Por exemplo, o pequeno dodecaedro estrelado e do grande dodecaedro estrelado são construídos com o mesmo módulo, porém com métodos diferentes. Neste artigo ilustraremos a construção do pequeno dodecaedro estrelado. O leitor poderá tentar a montagem do grande dodecaedro estrelado, pois os módulos são os mesmos. Não ilustraremos a sua construção.

Para montar o pequeno dodecaedro estrelado precisaremos de 30 módulos iguais. Utilize, de preferência, papel ofício branco ou papel específico para origami. O diagrama para a construção do módulo está descrito na tabela 2 e a construção do poliedro está descrita na Tabela 3.

Tabela 2: Módulo do pequeno dodecaedro estrelado e grande

\begin{tabular}{|c|c|} 
Faça um Quadrado e divida-o em 3 \\
partes iguais.
\end{tabular}


Tabela 3: Construção do pequeno dodecaedro estrelado

\begin{tabular}{|c|c|c|}
\hline $\begin{array}{l}\text { 1-30 módulos do Pequeno } \\
\text { Dodecaedro Estrelado. }\end{array}$ & $\begin{array}{l}2 \text { - As peças se encaixam de } \\
\text { acordo com a figura acima. }\end{array}$ & $\begin{array}{l}3 \text { - O encaixe perfeito possui } \\
\text { esse aspecto. }\end{array}$ \\
\hline $\begin{array}{l}4 \text { - Encaixe } 5 \text { módulos como a } \\
\text { figura. }\end{array}$ & $\begin{array}{l}5 \text { - Faça "bico" encaixando o } \\
\text { último módulo no primeiro. }\end{array}$ & $\begin{array}{l}6 \text { - Agora encaixe } 1 \text { peça em } \\
\text { cada abertura da estrela. }\end{array}$ \\
\hline $\begin{array}{l}\text { 7-Após o encaixe, a peça } \\
\text { terá esse aspecto. }\end{array}$ & $\begin{array}{l}8 \text { - Escolha outro "bico" e } \\
\text { repita os passos 4, 5, } 6 \text { e } 7 .\end{array}$ & 9 - Aspecto após os encaixes. \\
\hline $\begin{array}{l}10 \text { - Continue os encaixes } \\
\text { seguindo o passo } 8 \text {. }\end{array}$ & $\begin{array}{l}11 \text { - Faltam apenas } 5 \\
\text { módulos para terminar. }\end{array}$ & $\begin{array}{l}12 \text { - Terminado o Pequeno } \\
\text { Dodecaedro Estrelado. }\end{array}$ \\
\hline
\end{tabular}

Para obter um melhor resultado basta utilizar cola para deixar os módulos mais fixos e pintar as faces do poliedro com cores diferentes. Veja a Figura 10. 


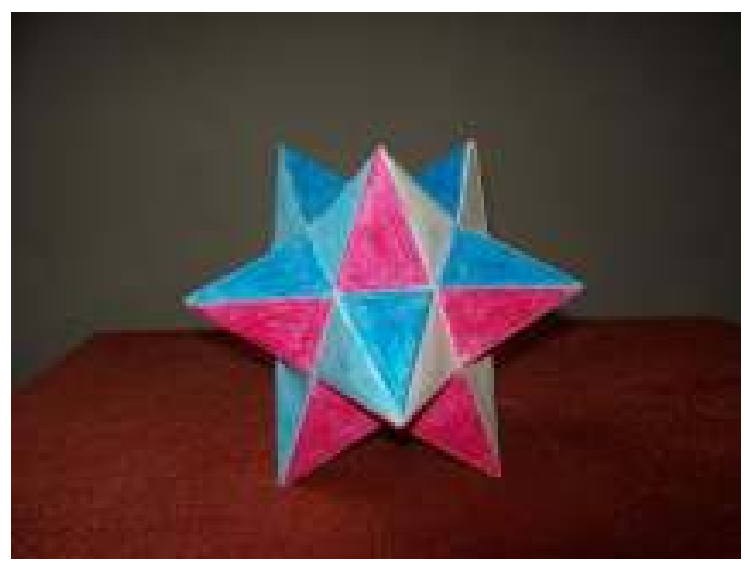

Figura 10: Pequeno dodecaedro estrelado

A exemplificação dos módulos e a construção dos poliedros estrelados com origami não estão muito presentes nos sítios da Internet. Essa é outra contribuição do presente trabalho. Estamos desenvolvendo módulos para a construção de todos os quatro poliedros estrelados regulares e também vídeos didáticos que mostram a construção desses módulos. Por exemplo, a Figura 11 ilustra, mediante o uso do vídeo, a construção do módulo do pequeno dodecaedro estrelado.

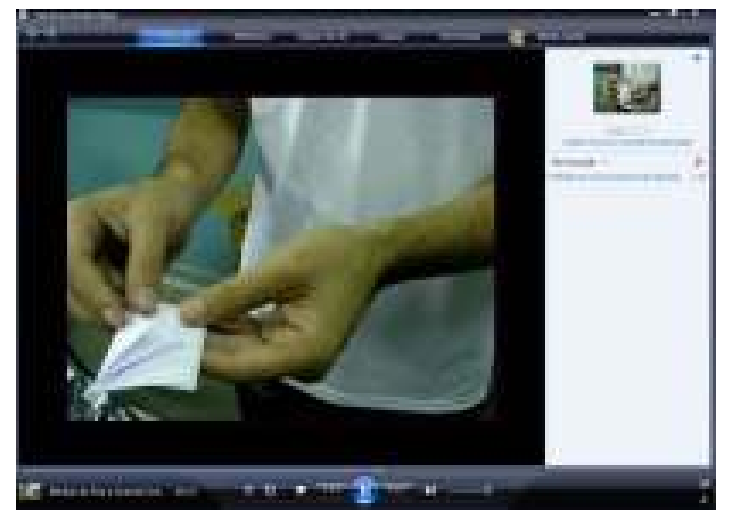

Figura 11 : Vídeo Didático. http://br.youtube.com/watch?v=jBK9PfoQ5-

$Q$

\section{Sites na internet}

Inicialmente fizemos uma varredura na internet em busca de sites com conteúdo correlato, de preferência em português. Para isso utilizamos o site de busca www.google.com.br utilizando as seguintes palavras-chave: poliedros estrelados, estrelação, origami e poliedros 
estrelados, planificação poliedros estrelados, poliedros animações, estellated polyhedra, polígonos estrelados e outros.

No orkut, utilizamos as comunidades relacionadas com Matemática, geometria, poliedros e origami como ferramenta de pesquisa para o nosso estudo. Separamos algumas comunidades, a saber:

A arte do Origami - http://www.orkut.com/Community.aspx?cmm=41045;

Origami Modular - http://www.orkut.com/Community.aspx?cmm=1297803;

Matemáticos (Origami) - http://www.orkut.com/Community.aspx?cmm=4483130.

Concluído o mapeamento identificamos que não existem muitos sites na internet sobre poliedros estrelados com idioma português. A grande maioria dos sítios estão em inglês ou espanhol. Abaixo segue a lista com alguns sites.

http://web.aanet.com.au/robertw/SmallStelDod.html

http://www.atractor.pt/simetria/matematica/docs/estrel.html

http://web.aanet.com.au/robertw/PolyNav/PolyNavigator.html

Este último site contém todas as informações sobre o software gratuito Great Stella que gera animações em três dimensões (3D) dos Poliedros Estrelados Regulares.

\section{Planificações}

A construção de um modelo concreto de um poliedro pode ser obtida a partir de uma planificação do referido poliedro, seguida de cortes, dobraduras e colagens adequadas. Sua construção é possível através de cartolina, acetato ou folha de plástico rígido, que são bons materiais para este efeito.

Os modelos geométricos assim construídos ficam com as faces representadas através de cores diferentes, conforme mostra a Tabela 3.

Tabela 3: Planificações

\begin{tabular}{|l|l|}
\hline Poliedro & Planificação \\
\hline
\end{tabular}




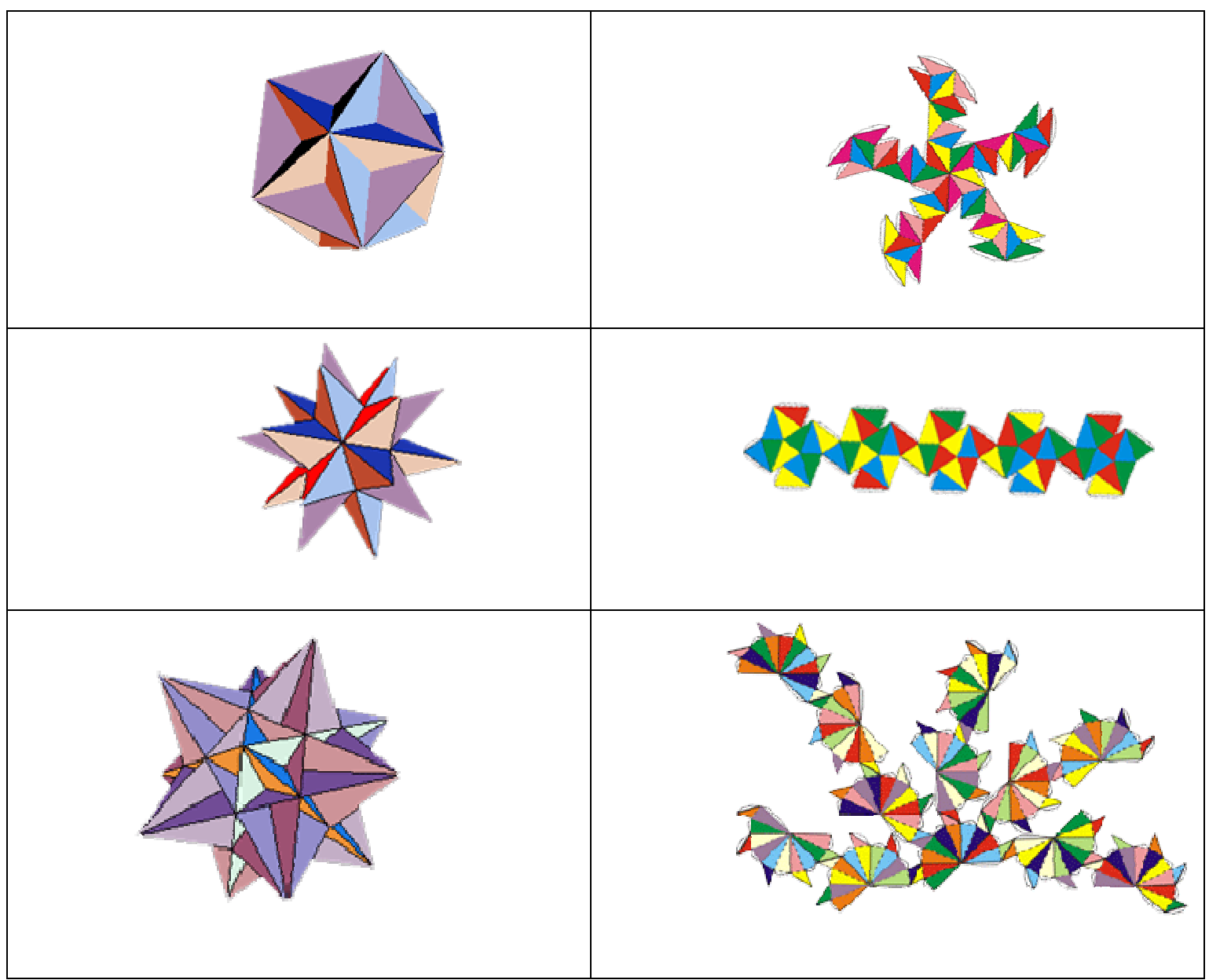

Fonte: http://www.korthalsaltes.com/collections/download/index.htm .

No site ttp://www.korthalsaltes.com/collections/download/index.htm é possível encontrar as planificações coloridas dos Poliedros de Kepler-Poinsot. Utilizamos este sítio para construir o Grande Icosaedro. O resultado obtido depende do tipo de papel utilizado. Utilize, de preferência, papel cartão ou cartolina.

Construímos o Grande Icosaedro com papel ofício e o resultado não foi satisfatório (Figura 12).

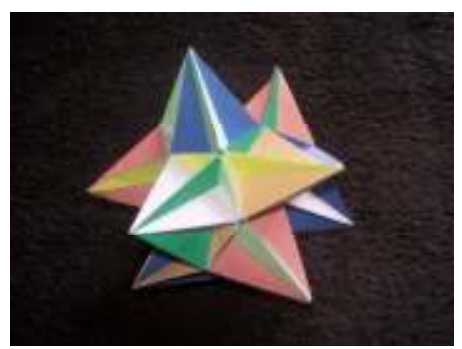

Figura 12 : Grande icosaedro 


\section{Animações - Software Great Stella}

Uma das maiores dificuldades do Ensino de Poliedros Estrelados é a visualização da estrelação do Poliedro, isto é, visualizar o encontro dos planos. Dessa forma, foi desenvolvida uma seqüência de animações dos Poliedros Estrelados para facilitar os alunos na visualização.

Partindo da idéia de alguns planos podemos generalizar para todos os seguintes. Por exemplo, na Figura 13 ilustramos o início da estrelação do dodecaedro.

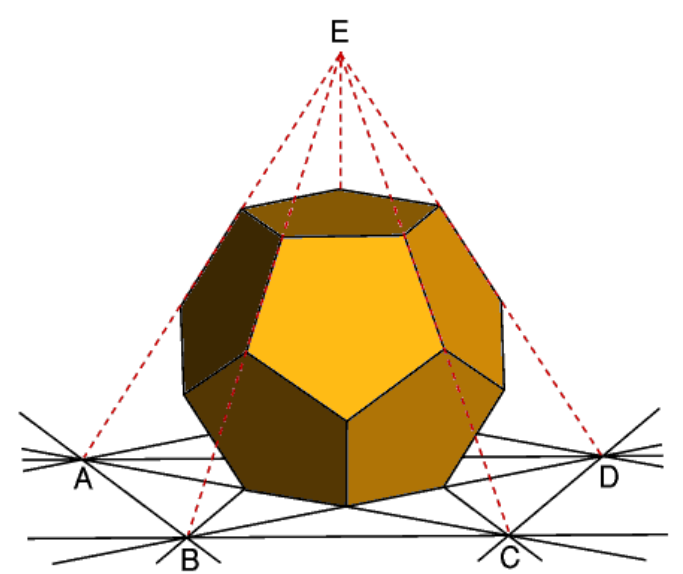

Figura 13: Encontro dos planos

Fonte: http://fortran.orpheusweb.co.uk/Poly/Ex/dodstl.htm.

Percebe-se que o vértice $E$ é formado pelo encontro dos planos. Com este tipo de ilustração destacamos também a importância de outro tipo de representação. Nosso processo de percepção visual vai se desenvolvendo nesse variado espectro representativo e dinâmico. Partindo da idéia da formação de um vértice generalizamos para todos os vértices. As Figuras 14, 15 e 16 ilustram seqüências de animação.

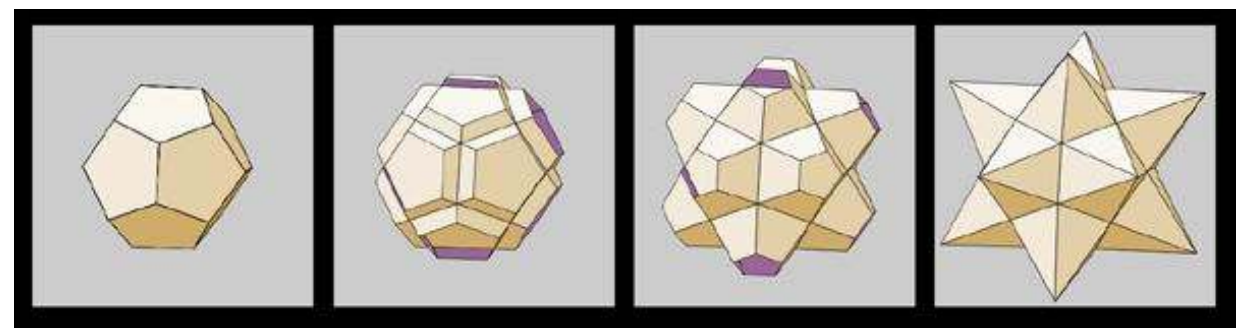

Figura 14: Animação do pequeno dodecaedro estrelado http://contidos.edu.xunta.es/premios/p2004/b/ poliedros/estrelas/estrelas.htm. 


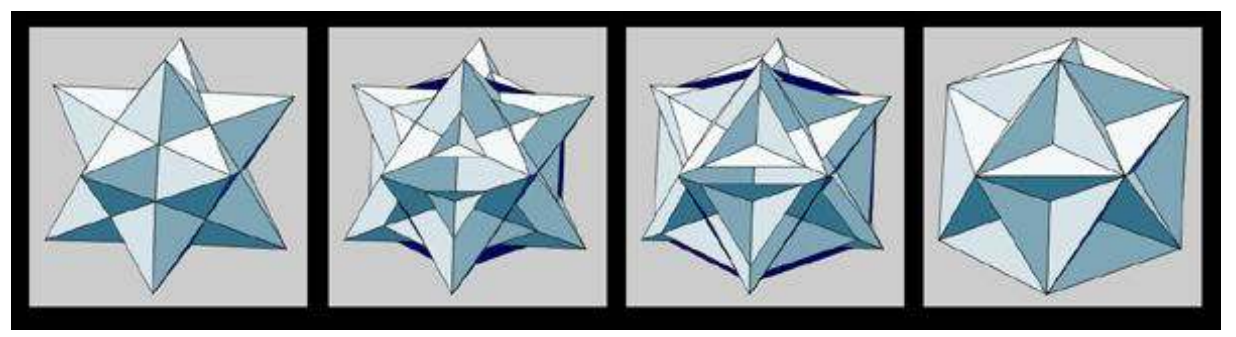

Figura 15: Animação do grande dodecaedro

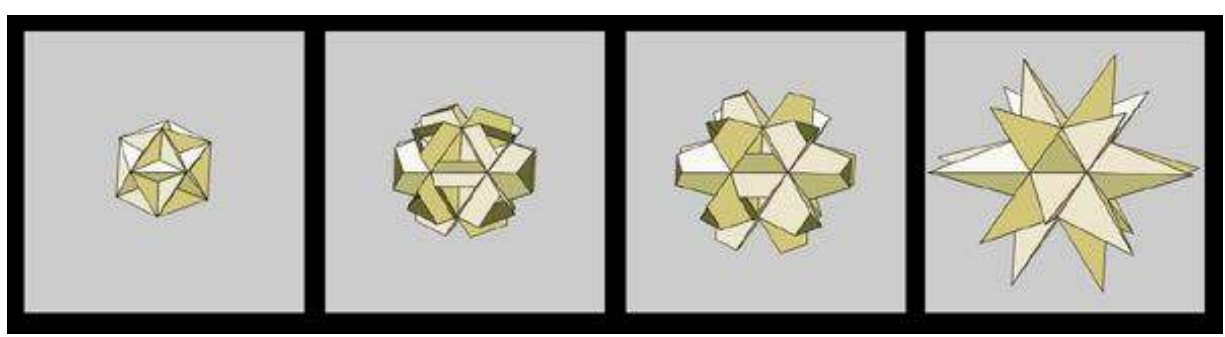

Figura 16: Animação do grande dodecaedro estrelado

Também podemos utilizar o software demonstrativo e gratuito Great Stella DEMO v. 3.5.1 disponibilizado em: http://www.download3k.com/Install-Great-Stella.html para o auxílio na construção do pensamento geométrico. Neste software é possível fazer rotações com os Poliedros Estrelados e também diversos outros tipos de Poliedros. Além de rotacioná-los, também podemos colorir cada face com uma cor diferente para melhorar a identificação de cada uma delas (Figura 17).

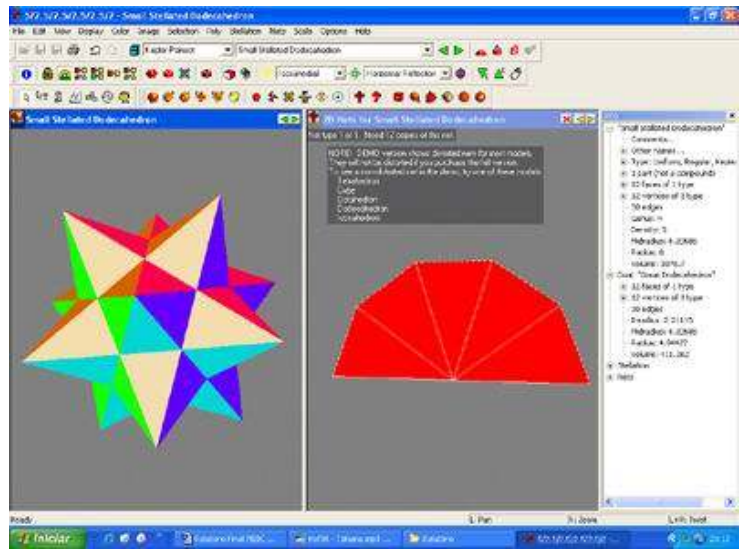

Figura 17: Software Great Stella 


\section{Algumas atividades}

As atividades (LEMOS e BAIRRAL, 2007) estão sendo elaboradas para uma dinâmica de aula que valoriza a descoberta conceituação, a construção manipulativa, a visualização e a representação geométrica, dentre outras.

Todas as atividades são implementadas com o auxílio do computador, através de animações digitais, sites na Internet e dobraduras com papel (Origami). Vejamos alguns exemplos de situações que podem ser implementadas.

\section{Atividade 1: Relembrando a definição de poliedros regulares}

Uma conversa inicial: Quantos poliedros regulares existem?

Existem 5 Poliedros Regulares. Os Poliedros Regulares são também conhecidos como Platônicos. São assim chamados por terem sido estudados e divulgados por Platão. São conhecidos como Regulares, pois todas as faces, ângulos e ângulos entre as faces são sempre os mesmos.

\section{Atividade 2 - "Estrelação 1": 0 que significa estrelar um polígono?}

O que significa estrelar um polígono?

Se prolongarmos os lados de um quadrado e de um pentágono, os resultados obtidos serão muito diferentes. $O$ prolongamento dos lados do quadrado não define um novo polígono, porém no pentágono obtemos o pentagrama. 0 processo que permite obter o pentagrama se chama estrelação (o polígono dá origem a uma estrela). Se o processo de estrelação gerar um novo polígono e, se o polígono gerado não for dado pela sobreposição de polígonos diremos que o polígono é estrelado.

\section{Atividade 3 - "Estrelação 2": 0 que significa estrelar um poliedro regular?}

Partindo da idéia de estrelação de polígonos como deve ser feita a estrelação de poliedros?

O processo de obter sólidos estrelados é semelhante ao dos polígonos, ou seja, prolongam-se as faces de sólidos e, caso elas se encontrem, obtemos os Poliedros Estrelados.

\section{Atividade 4 - Reconhecendo os Poliedros Regulares Estrelados}

Quantos poliedros estrelados regulares (ou poliedros regulares estrelados) existem?

Existem 4, o pequeno dodecaedro estrelado, o grande dodecaedro, o grande dodecaedro estrelado e o grande icosaedro. 


\section{Atividade 5 - É possível planificar esses poliedros?}

Como os poliedros regulares os poliedros regulares estrelados também podem ser planificados. A construção de um modelo concreto de um poliedro pode ser obtida a partir de uma planificação do referido poliedro, seguida de cortes, dobraduras e colagens adequadas. Sua construção é possível através de cartolina, acetato ou folha de plástico rígido, que são bons materiais para este efeito. Os modelos geométricos assim construídos ficam com as faces representadas através de cores diferentes.

Atividade 6: Construção do Pequeno Dodecaedro Estrelado mediante procedimentos com dobraduras em papel (Origami)

Utilizando as Tabelas 2 e 3 , construir o pequeno dodecaedro estrelado.

\section{Atividade 7: Sites na Internet com animações dos poliedros estrelados}

O site http://mathworld.wolfram.com/Kepler-PoinsotSolid.html apresenta um quadro animado que mostra todos os Poliedros Estrelados Regulares, onde é possível rotacioná-los.

\section{Considerações finais}

Com o desenvolvimento dessa investigação estamos construindo alternativas didáticas que podem ser utilizadas pelo professor para o trabalho com Poliedros Estrelados no Ensino Médio. Neste artigo exemplificamos animações em 3D com Poliedros Estrelados, divulgamos sítios na Internet que exploram o tema, sugerimos algumas possíveis atividades e ilustramos a construção dos Poliedros Estrelados com dobraduras e planificações. Além de inovações curriculares acreditamos que os resultados da pesquisa contribuem com novas perspectivas para a análise do aprendizado matemático mediante o uso de planificações, uso de vídeo, dobraduras e animações em 3D.

Até o presente momento vimos que existem poucos sites sobre os Poliedros Estrelados em português. Precisamos investir na construção destes em nosso idioma. Identificamos, também, que figuras dos Poliedros e planificações são as mais apresentadas nas páginas consultadas. Ao contrário, os módulos para construção, não.

Temos visto que anteriormente ao estudo dos Poliedros Estrelados é importante abordar os Poliedros Regulares e o processo de estrelação em polígonos. Nesta perspectiva, temos visto que a seqüência didático-conceitual (Polígonos Estrelados $\rightarrow$ Poliedros Regulares $\rightarrow$ Poliedros Regulares Estrelados) mostra-se importante. No entanto, a arquitetura de aula onde referida sequenciação é posta em prática não é linear e hierárquica, mas hipertextual e sem caminhos prédefinidos, pois esta arquitetura inter-relaciona processos cognitivos, comunicativos e 
representacionais variados. Tais processos são deflagrados individual e coletivamente mediante o uso de atividades que objetivam a descoberta, a conceituação, a construção e a manipulação (convencional ou via mouse) de modelos de Poliedros.

O uso do computador é importante, porém não é suficiente, pois o processo de visualização de Poliedros Estrelados não é simples. Além de animações e explorações em 3D a construção do pensamento geométrico implica manipulação e diferentes representações. Acreditamos que o mapeamento de materiais na rede que estamos realizando e os diferentes recursos que estamos construindo ajudarão na composição de um novo cenário para o aprendizado matemático. Sendo assim, esperamos que o leitor sinta-se motivado para construir o seu kit-pedagógico para usar em sala de aula.

A motivação e contribuição dos alunos para a construção dos materiais são muito importantes para o seu processo formativo, pois fazendo e estando motivado, se aprende. Temos consciência de que a construção desses materiais não será aplicada a todos os assuntos da geometria espacial, mas seguramente disponibilizará uma diversificação e integração de novos e diversificados meios didáticos. Também, desenvolverá no docente a criatividade para elaborar aulas de matemática mais dinâmicas e desafiadoras.

Em nossas implementações temos visto que a beleza estética dos Poliedros Estrelados despertam o interesse nos professores para o seu trabalho em aula e, dos alunos, a motivação pelo seu aprendizado. Temos visto que o aprofundamento da análise do desenvolvimento conceitual de polígonos e poliedros estrelados faz-se necessário. Nesta perspectiva, no momento atual da pesquisa estamos (i) analisando como professores de matemática desenvolvem o conceito de poliedros estrelados mediante a realização da seqüência didática que estamos propondo. Do ponto de visto didático, estamos (ii) elaborando atividades com outros recursos informáticos; (iii) aprimorando a construção do grande dodecaedro, do grande dodecaedro estrelado e do grande icosaedro com dobraduras, e (iv) elaborando vídeos didáticos que mostram a construção dos módulos e Poliedros Estrelados.

\section{Referências}

ABRANTES, P. Investigações em Geometria na Sala de Aula. Disponível em: http://ia.fc.ul.pt/textos/p_153-167.PDF. Acesso em 30/10/2007.

AGUIAR, A. Uso de animações em 3D em geometria espacial. UFRRJ/DEMAT. Monografía de conclusão de curso de Graduação em Matemática. Seropédica, 2006.

BASTOS, R. Geometria no currículo e pensamento matemático. Disponível em: http://www.apm.pt/apm/revista/educ52/educ52_2.htm. Acesso em: 05/10/2007 
BRASIL. Orientações curriculares paro o Ensino Médio: Ciências da Natureza, Matemática e suas Tecnologias. Brasília: MEC/Secretaria de Educação Básica, 2006, p.69-98.

BRASIL. Parâmetros Curriculares Nacionais. MEC/SEF, 1997.

KALEFF, A. M. Vendo e Entendendo Poliedros. Niterói: EDUNFF, 2004. 2ª ed.

LEMOS, W. G. Animações Digitais para o Aprendizado de Poliedros Estrelados no Ensino Médio. Relatório Final PIBIC/UFRRJ/DPPG/CNPq, 2007. 42p.

LEMOS, W. G.; BAIRRAL, M. Poliedros Estrelados com Animações em 3D e Dobraduras. Anais do IX ENEM, Belo Horizonte, 18-21/07/2007. Em CD-ROM.

LEMOS, W. G.; BAIRRAL, M. A Construção do Conceito de Poliedros Estrelados por Professores de Matemática. Livro de resumos da XVII Jornada de Iniciação Científica da UFRRJ. Seropédica: DPPG, 2007. Em CD-ROM.

LEMOS, W. G.; BAIRRAL, M. Aprendizado de Poliedros Estrelados Através de Animações e Dobraduras no Ensino Médio. Livro de resumos da XVI Jornada de Iniciação Científica da UFRRJ. Seropédica: DPPG, 2006. Em CD-ROM.

LORENZATO, S. O Laboratório de Ensino da Matemática na Formação de Professores. Campinas, SP: Autores Associados, 2006.

PETER, H.; PEDERSEN, J. Build Your Own Polyhedra. Parsippany, NJ: Dale Seymour Publication, 1994.

SARAIVA, M. J.; COELHO, M. I.; MATOS, J. M. Ensino e Aprendizagem da Geometria. Lisboa: SEM/SPCE, 2002.

VELOSO, E. Geometria: temais actuais. Lisboa: IIE, 1998.

Wellington Gonçalves Lemos - UFRRJ - Universidade Federal Rural do Rio de Janeiro. wglemos@click21.com.br

Marcelo Almeida Bairral - UFRRJ - Universidade Federal Rural do Rio de Janeiro. mbairral@ufrrj.br 